\title{
FLOTAC Technique for Soil-Transmitted Helminth Infection Diagnosis
}

\author{
Helena Ullyartha Pangaribuan,, ${ }^{1,2}$ Heri Wibowo, ${ }^{3}$ Taniawati Supali ${ }^{3}$ \\ ${ }^{1}$ National Institute of Health Research and Development, Ministry of Health RI, Jakarta, Indonesia, \\ ${ }^{2}$ Directorate of Vector Borne and Zoonotic Diseases Prevention And Control, Ministry of Health, Indonesia, \\ ${ }^{2}$ Departement of Parasitology, Faculty of Medicine, Universitas Indonesia Jakarta, Indonesia
}

\begin{abstract}
Human helmintiasis is a neglected disease with significant economic impacts caused by its effects on performance and cognition. The burden of many helminth infections is not well understood due to the lack of progress in detecting low-intensity infection in elimination programs. Furthermore, the decision for individual and community treatments, as well as the community-based control program evaluation, obviously depends on the technics used for parasitological diagnostic. A well-established diagnostic technic will be beneficial to detect and eliminate the disease. Therefore, this study aimed to compare the performance of FLOTAC and FECT technics for detecting helminth infections in human stool. A total of 149 fecal specimens were collected from schoolchildren in Nangapanda village, Ende District, East Nusa Tenggara Province in 2012. The sensitivity of both technics was analyzed using the kappa analysis. Positive results from both technics were used as the gold standard. The sensitivity of FLOTAC for diagnosing T. Trichiura, A. lumbricoides and hookworm infections were $100 \%, 100 \%$, and $82 \%$, respectively, while the sensitivity of FECT was $80 \%, 7 \%$, and $18 \%$, respectively. FLOTAC yielded considerably higher mean faecal egg counts $(11,452,1,038$, and 19 eggs per gram stool (EPG) for A. lumbricoides, T. Trichiura, and hookworm). FLOTAC technique was considerably more sensitive than FECT in diagnosing soiltransmitted helminth infections. In conclusion, FLOTAC can be used as a diagnosis tool for future helminth control programs.
\end{abstract}

Keywords: Diagnosis, FLOTAC, soil-transmitted helminth

\section{Penggunaan Teknik FLOTAC pada Diagnosis Infeksi Cacing Usus}

\begin{abstract}
Abstrak
Cacingan termasuk salah penyakit yang terabaikan dan masalah kesehatan masyarakat yang berdampak signifikan terhadap ekonomi, yaitu melalui kinerja dan kognitif. Sementara morbiditas cacingan sering tidak dipahami dengan baik dalam program eliminasi karena terbatasnya sensitivitas deteksi infeksi pada daerah yang intensitas infeksinya rendah. Selain itu, akurasi teknik diagnostik parasitologi penting dalam penentuan pengobatan individu dan masyarakat serta evaluasi program pengendalian melalui pengobatan pada komunitas (masyarakat). Penelitian ini membandingkan dua teknik, yaitu FLOTAC dan FECT dalam mendiagnosis infeksi cacing pada sampel tinja manusia. Sebanyak 149 spesimen feses dikumpulkan dari anak-anak sekolah di Nangapanda, Ende Kabupaten, Provinsi Nusa Tenggara Timur tahun 2012. Sensitivitas dari kedua teknik tersebut diukur menggunakan analisis Kappa. Hasil positif pada kedua teknik atau hasil kombinasi yang digunakan sebagai gold standar. Sensitivitas FLOTAC dalam mendiagnosis T. trichiura, A. lumbricoides dan cacing tambang adalah masing-masing 100\%, 99\% dan 82\%, sedangkan sensitivitas FECT adalah 82\%, 75\% dan 18\%. Teknik FLOTAC memperoleh rata - rata fecal egg count $(11.452,1038,19$ telur per gram tinja (EPG) untuk A. lumbricoides, T. trichiura, dan cacing tambang. Teknik FLOTAC lebih sensitif dibandingkan teknik FECT untuk mendiagnosa infeksi cacing usus. Simpulan, FLOTAC sangat mungkin menjadi alat diagnosis untuk program pengendalian cacing di masa depan.
\end{abstract}

Kata kunci: Diagnosis, FLOTAC, infeksi cacing usus

Corresponding author: Helena Ullyartha Pangaribuan, National Institute of Health Research and Development, Ministry of Health RI, Jakata, Indonesia, Email: helenartha@yahoo.co.uk 


\section{Introduction}

Helminthic parasites afflict more than a quarter of the world's population, causing significant disease and disability. Ascaris lumbricoides, Trichuris trichiura, and hookworm (Ancylostoma duodenale and Necator americanus) are known as soil-transmitted helminthiasis because they require soil for the development of the infective form $^{1}$

According to Montesor et $\mathrm{al}^{2}{ }^{2}$ preventive chemptherapy (PC) implemented between 2010 and 2015 saved over 549000 DALYs in 2015 , which is equivalent to $44 \%$ of the disease burden (in DALYs) in 2010 prior to global STH control program expansion.

Helmintiasis is a major public health concern in Indonesia. A cross-sectional survey of 16 villages was conducted in Semarang demonstrate that STH overall prevalence was 33.8\%. ${ }^{3}$

The primary method of preventing infection STH is treated on a regular basis with a fourdrug regimen recommended by WHO, namely mebendazol (MBD), albendazole (ALB), levamisole, and pyrantel. ${ }^{4}$

Antihelmintic Cure Rate (CR) and Egg Reduce Rate (ERR) were two indicators that were used to determine therapeutic effectiveness in individuals (ERR). The ERR indicator is preferred in public health. Although the WHO recommends parasitological examinations every few years for large-scale treatment programs, this is rarely done, and thus often occurs in the absence of a coherent long-term strategy and standard monitoring protocol. ${ }^{5}$ When infection levels are typically highest, a diagnostic test with moderate sensitivity is acceptable; however, the chosen tool must be simple to use, cost-effective, and capable of testing large populations in a high-throughput manner. ${ }^{6}$

The most common method of diagnosis is to calculate the EER using the Kato-Katz and concentration techniques. However, the Kato-Katz method of calculating the EPG has limitations for use in the field to monitor the STH elimination program, particularly because stool samples must be read within 30-60 minutes of collection to avoid hookworm egg damage. The concentration method can be used to calculate the density of infection in this manner, but the calculations are less sensitive than the Kato- Katz technique, especially when the density of eggs is low (4-5 eggs) ${ }^{7}$

According to WHO, if the number of eggs in stool specimens remains low, direct examination is not recommended. Concentration techniques are required when direct examination fails to find the parasite despite the patients exhibiting clinical symptoms of parasitic infections and to detect the worm Schistosoma and Taenia infection. The WHO recommended concentration technique is formalin formalin ether or ethyl acetate (FECT). The FECT was more effective than other methods in detecting hookworm, Trichuris trichiura, and small liver flukes. ${ }^{8}$

An Italy researcher have developed a new technique which is called FLOTAC to diagnosis helminth infection. FLOTAC promising diagnosis technique is sensitive, accurate and appropriate for qualitative and quantitative analysis. FLOTAC method utilizes apparatus, a cylindrical device with two $5 \mathrm{~mL}$ flotation chamber, which allows up to $1 \mathrm{~g}$ of feces to be prepared for microscopic analysis. Compared to current diagnostic methods more widely used to detect human parasites such as Kato-Katz and concentration techniques. Techniques FLOTAC showed a higher sensitivity and accuracy. All FLOTAC technique can be performed on fresh stool and stool samples preserved, and takes about 12-15 minutes of preparation time prior to review by microscopis. ${ }^{9}$

The sensitivities of a single Kato-Katz for diagnosing of T. trichiura, A. lumbricoides and hookworm infections were $76.6 \%, 67.8 \%$ and $19.6 \%$, respectively, while the sensitivity of FLOTAC was $100 \%$ for all the three soiltransmitted helminth species. While T. trichiura, A. lumbricoides, and hookworm infections were found in $44.6 \%$ (121/271), $21.7 \%$ (59/271), and $3.7 \%(10 / 271)$ of a single Kato-Katz technique. Kappa values of $0.74,0.73$, and 0.28 were found for Ascaris lumbricoides, Trichuris trichiura, and hookworm, respectively. For each of the three soil-transmitted helminths, a single FLOTAC showed significantly more sensitive than a single Kato-Katz. ${ }^{10}$

Filariasis and soil-transmitted helminthiases programs, such as mass drug administration are now being implemented as part of the Indonesian National elimination. As a result, the sensitive diagnostic technique must be employed in order to support the elimination program's success. Therefore, in this study, we will compare the concentration technique, namely FECT with FLOTAC, in order to assess its sensitivity and ability to identify people who are not infected with STH infection or negative predictive values, as well as egg intensity in elementary school children where STH is endemic. 


\section{Methods}

The research was carried out in Ende's Nangapanda District, East Nusa Tenggara Province1n 2012. To assess sensitivity and negative predictive value (NPV), samples were obtained by calculating the proportion of the number of single subjects.. The study included 149 schoolchildren from low-income communities where intestinal worms were prevalent. The sample size was calculated using the formula for a single proportion, namely the total number of subjects to assess sensitivity or specificity using disease prevalence as a reference. ${ }^{11}$

$\mathrm{n}=\underline{\mathrm{Z}} \underline{\alpha^{2}} \underline{\mathrm{d}^{2}} \underline{\mathrm{PQ}}$

where $\mathrm{n}$ is Total Sample, $\mathrm{p}$ is Sensitivity for FLOTAC technique $=80 \%, \mathrm{Q}$ is $10 \%$, $\mathrm{d}$ is deviation of $10 \%, \mathrm{Z} \alpha$ is If the $95 \%$ confidence interval, $=0.05$ then $\mathrm{Z} \alpha=1.96$, So: $\mathrm{n}=\left(1,96^{2} \times 0,90 \times 0,1\right) / 0,1^{2}$ $\mathrm{n}=(3,8146 \times 0,09) / 0,01, \mathrm{n}=30,51 \sim 31$

Sample size calculation for sensitivity and specificity analysis for prevalence of disease from $65 \%$ in Ende Regency, East Nusa Tenggara Province is $65 \%$, so the number of subjects is $100 / 65 \times 31=48$. A sample size of at least 48 people was required for this study.

Stool samples were sent to the Parasitology Laboratory at the Faculty of Medicine, University of Indonesia, in Jakarta. Each sample was placed in a small tube containing $10 \mathrm{~mL}$ of sodium acetate-acetic acid-formalin (SAF) solution. The SAF fixed sample processed by an ether concentration and FLOTAC technique was largely as described by Cringoli. The reagent or flotation solution (FS) used in this study is saturated sodium chloride $(\mathrm{NaCl}){ }^{9}$

The FS chosen has been determined by an element of the parasite that is relevant to the purpose of the study. NACL is dissolved in 1 liter of $40-50^{\circ} \mathrm{C}$ warm water until all of the salt has dissolved (500 g) and the rest has settled to the bottom of the container. SODIUM NITRATE is dissolved in water with the help of a magnetic stirrer. To ensure that solution is fully saturated, leave it at room temperature overnight. With a hydrometer, measure the saturated solution's s.g. (1.2), noting that the s.g. of the saturated solution will vary slightly depending on the ambient temperature. For at least a month, maintain the flotation solution at room temperature (20$25^{\circ} \mathrm{C}$ ). We need to weigh $10 \mathrm{~g}$ of feces before homogenizing it with $90 \mathrm{~mL}$ of tap water. The suspension was filtered through a wire mesh screen with a $250 \mathrm{~m}$ aperture, and tubes (15 $\mathrm{mL}$ ) were filled to $10 \mathrm{~mL}$ with the filtrate. The supernatant was removed after centrifugation at $1500 \mathrm{rpm}$ for 3 minutes, and the tubes were refilled to $6 \mathrm{~mL}$ with the appropriate flotation solution. One chamber of a FLOTAC was filled with the homogenized solution after vortex mixing the sample $(5 \mathrm{~mL})$. After centrifugation at $1000 \mathrm{rpm}$ for 5 minutes, the FLOTAC was rotated and parasite elements were counted at 100 magnification. To ensure that the chambers were completely full and to avoid small air bubbles, a 6-mL volume has been used rather than the suggested 5-mL volume. ${ }^{9}$

Data was entered into Microsoft excel Office 2007 and analyzed with SPSS software for Windows version 17 . The sensitivity and NPV were calculated using the CAT maker software developed by Douglas Badenoch of the Centre for Evidence-Based Medicine (CEBM,University of Oxford, England). The CAT maker software is a tool that assists us in creating Critically Appraised Topics, or CATs, for key articles we encounter about therapy, diagnosis, prognosis, aetiology/ harm, and systematic reviews of therapy. The CAT maker software as the toolkit adds to the arsenal of critical appraisal tools currently available and is especially useful in assessing evidence from a wide variety of research design. ${ }^{12}$

The statistic was used to compare the agreement between the two techniques for diagnosing STH infection (FECT versus FLOTAC). The sensitivity (the proportion of true positives in the population) and negative predictive value (the proportion of individuals with a negative test result who are correctly diagnosed) of each method have been calculated, with the combined results from each technique serving as the diagnostic "gold" standard. This method maximized sensitivity values through detecting STH (A.lumbricoides, T.trichiura, hookworm) eggs using any of the techniques used.

Ethics approval was obtained from the Faculty of Medicine University of Indonesia's research ethics committee (reference no. 194/PT02.FK/ Etik/2006). The study was ethically approved by The study's purpose and procedure were clearly explained to selected samples (schoolaged children, and the faecal samples have been provided by children who agreed to provide their stools). Furthermore, at the end of this study, all samples (school-aged children), including those who tested positive for helminth infection, were given antihelminthic drug albendazole $400 \mathrm{mg}$. 


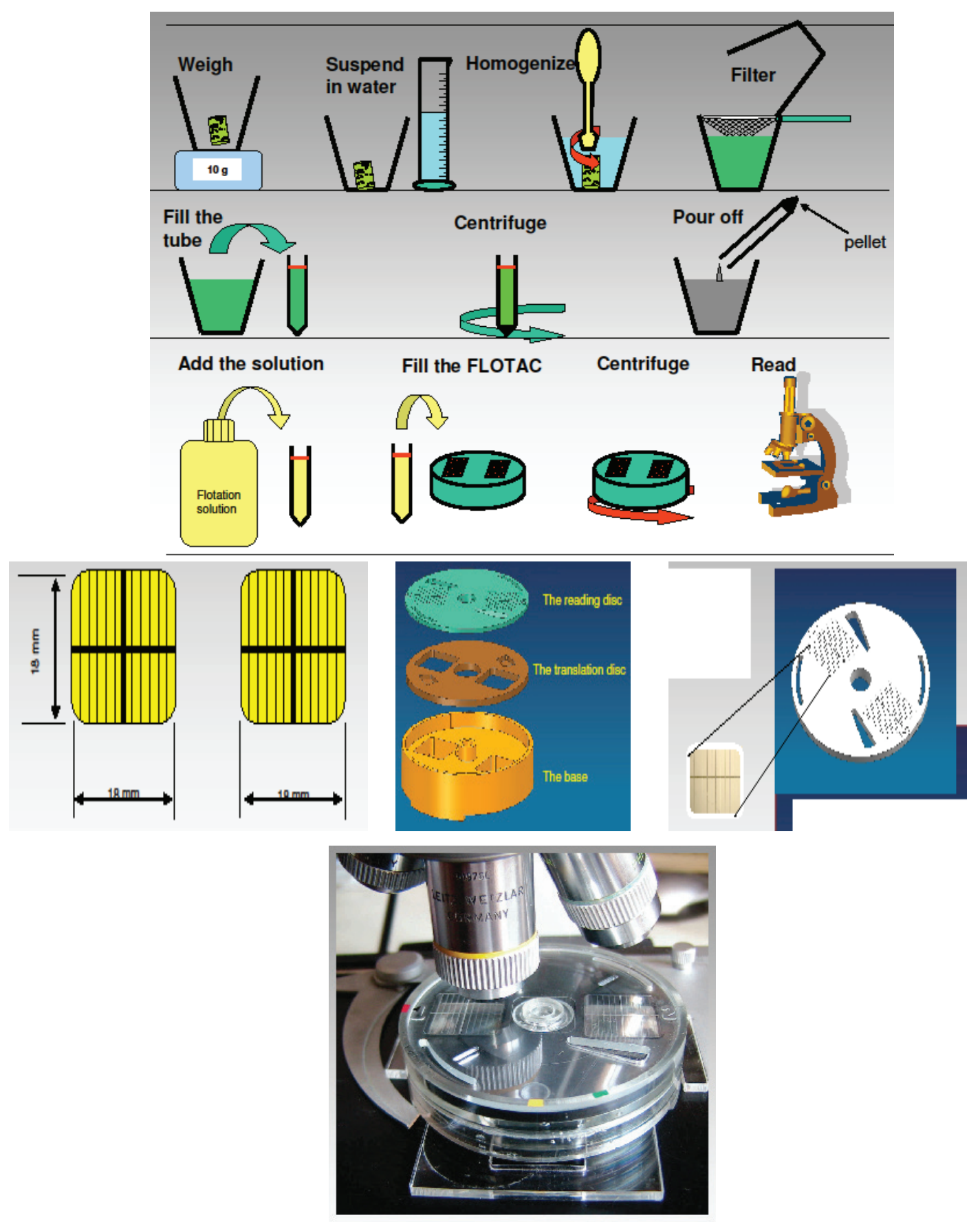

Figure 1 FLOTAC Technique Procedure ${ }^{13}$

\section{Results}

The research was conducted in four elementary schools which included 149 school-age children and the analysis shows the variation of prevalence rates ranging between 37.1462.69\%. SD Pau Pau has the highest prevalence of $62.69 \%$. This study revealed that 78 (57.68\%) boys and 71 (49.30\%) girls providing their stool. The examination technique (FECT) is $53 \%$ $(79 / 149)$, and the FLOTAC examination is 64.4 $\%$ (96/149), shows a high morbidity rate for STH parasites. However, it cannot be distinguished from the risk of disease infection in both boys and girls. The incidence of worm infection by age group was divided by class (I to VI) in that study, 
HU Pangaribuan et al: FLOTAC Technique for Soil-Transmitted Helminth Infection Diagnosis

Table 1 Distribution of Helminthiasis Cases And The Causative Species By Gender, Age

\begin{tabular}{|c|c|c|c|c|c|c|}
\hline \multirow{2}{*}{ Characteristic } & \multirow{2}{*}{$\begin{array}{c}\text { No.of } \\
\text { Sample } \\
\text { Examined } \\
(\mathrm{n}=149)\end{array}$} & \multirow{2}{*}{$\begin{array}{c}\text { No. of } \\
\text { Positive }\end{array}$} & \multirow{2}{*}{ \%age (\%) } & \multicolumn{3}{|c|}{ Infection by STH species } \\
\hline & & & & Al & $\mathrm{Tt}$ & $\mathrm{Ct}$ \\
\hline \multicolumn{7}{|l|}{ Sex } \\
\hline Male & 78 & 45 & 57.69 & 23 & 39 & 2 \\
\hline Female & 71 & 35 & 49.30 & 19 & 33 & 0 \\
\hline \multicolumn{7}{|l|}{ School grade } \\
\hline Grade I & 23 & 12 & 52.17 & 7 & 10 & 1 \\
\hline Grade II & 34 & 18 & 52.94 & 9 & 16 & 1 \\
\hline Grade III & 26 & 16 & 61.54 & 6 & 15 & 0 \\
\hline Grade IV & 16 & 8 & 50.00 & 5 & 7 & 0 \\
\hline Grade V & 18 & 8 & 44.44 & 5 & 7 & 0 \\
\hline Grade VI & 32 & 18 & 56.25 & 10 & 17 & 0 \\
\hline \multicolumn{7}{|l|}{ Areas of School } \\
\hline SD Katolik Arnoldus & 35 & 13 & 37.14 & 7 & 11 & 0 \\
\hline SD Negeri Nangapanda2 & 31 & 16 & 51.61 & 11 & 15 & 0 \\
\hline SD Negeri Puu'Au & 16 & 9 & 56.25 & 6 & 18 & 1 \\
\hline SD Negeri Puu'Pau & 67 & 42 & 62.69 & 19 & 30 & 1 \\
\hline
\end{tabular}

with results ranging from $50 \%$ to $76.92 \%$. As a result, nearly every grade level had an infection rate greater than $50 \%$.

FLOTAC detected 51 of 149 samples, while FECT detected 42 A. lumbricoides cases. Both of the above techniques appear to have high agreement attributes in identifying the species A. lumbricoides $(\mathrm{p}=0.73)$. The FECT technique detects 72 cases of T.trichiura, while the FLOTAC technique detects 91 cases. The agreement between the two methods for detecting T.trichiura appears to be high $(\mathrm{p}=0.86)$. The FECT technique, on the other hand, detects only two cases of hookworm, whereas FLOTAC detects nine cases. In both techniques, positive hookworm species were not always found to be the same for both techniques. The agreement between the two techniques in detecting

Table 2 A.lumbricoides, T.trichiura, Hookworm Infection Status Diagnosing with FECT and FLOTAC Technique

\begin{tabular}{|c|c|c|c|c|c|c|}
\hline \multirow{2}{*}{ Species } & \multirow[t]{2}{*}{ FECT } & \multicolumn{3}{|c|}{ FLOTAC } & \multirow{2}{*}{$\begin{array}{c}\text { McNemar Test } \\
\text { Cl 95\% }\end{array}$} & \multirow{2}{*}{$\begin{array}{c}\text { k agreement } \\
\text { (p) }\end{array}$} \\
\hline & & Positive & Negative & Total & & \\
\hline \multirow[t]{3}{*}{ A. lumbricoides } & Positive & 42 & 0 & 42 & 0.001 & $0.72(<0.001)$ \\
\hline & Negative & 9 & 98 & 107 & & \\
\hline & Total & 51 & 98 & 149 & & \\
\hline \multirow[t]{3}{*}{ T. Trichiura } & Positive & 71 & 1 & 72 & 0.065 & $0.86(<0.001)$ \\
\hline & Negative & 20 & 57 & 77 & & \\
\hline & Total & 89 & 58 & 149 & & \\
\hline \multirow[t]{3}{*}{ Hookworm } & Positive & 0 & 2 & 2 & 0.004 & $-0.022(<0.001)$ \\
\hline & Negative & 9 & 138 & 147 & & \\
\hline & Total & 9 & 140 & 149 & & \\
\hline \multirow[t]{3}{*}{ Any infection* } & Positive & 80 & 0 & 80 & 0.001 & $0.76(<0.001)$ \\
\hline & Negative & 17 & 52 & 70 & & \\
\hline & Total & 97 & 52 & 149 & & \\
\hline
\end{tabular}


HU Pangaribuan et al: FLOTAC Technique for Soil-Transmitted Helminth Infection Diagnosis

Table 3 Sensitivity and NPV of the FLOTAC and FECT Technique

\begin{tabular}{lcccc}
\hline \multirow{2}{*}{ Species } & \multicolumn{2}{c}{ Sensitivity(95\%CI) } & \multicolumn{2}{c}{ NPV (95\%CI) } \\
\cline { 2 - 5 } & FLOTAC & FECT & FLOTAC & FECT \\
\hline A.lumbricoides & $100 \%(100-100 \%)$ & $82 \%(72-93 \%)$ & $100 \%(100-100)$ & $92 \%(86-97 \%)$ \\
T.Trichiura & $99 \%(97-100 \%)$ & $78 \%(70-87 \%)$ & $98 \%(95-100 \%)$ & $75 \%(65-84 \%)$ \\
Hookworm & $82 \%(59-100 \%)$ & $18 \%(--5-41 \%)$ & $99(9-100 \%)$ & $94 \%(90-98 \%)$ \\
Any infection* & $100 \%(100-100 \%)$ & $82 \%(75-90 \%)$ & $100 \%(100-100 \%)$ & $75 \%(65-86 \%)$ \\
\hline
\end{tabular}

* Individuals infected with at least one of the species

Table 5 Variation in the Density of $A$. lumbricoides, T. trichiura, and Hookworm Infection Using FECT and FLOTAC Techniques

\begin{tabular}{|c|c|c|}
\hline Species & FECT & FLOTAC \\
\hline \multicolumn{3}{|l|}{ A.lumbricoides } \\
\hline No infection & 108 & 99 \\
\hline $\begin{array}{l}\text { Light } \\
\text { (1-4999 epg) }\end{array}$ & 41 & 47 \\
\hline $\begin{array}{l}\text { moderate } \\
\text { (5000-49999 epg) }\end{array}$ & 0 & 3 \\
\hline Total & 149 & 149 \\
\hline \multicolumn{3}{|l|}{ T.trichiura } \\
\hline No infection & 77 & 60 \\
\hline $\begin{array}{l}\text { Light } \\
\text { (1-999 epg) }\end{array}$ & 72 & 88 \\
\hline $\begin{array}{l}\text { moderate } \\
\text { (1000-9999 epg) }\end{array}$ & 0 & 1 \\
\hline Total & 149 & 149 \\
\hline Hookworm & & \\
\hline No infection & 147 & 140 \\
\hline $\begin{array}{l}\text { Light } \\
\text { (1-1999 epg) }\end{array}$ & 2 & 9 \\
\hline $\begin{array}{l}\text { moderate } \\
\text { 2000-3999 epg) }\end{array}$ & 0 & 0 \\
\hline Total & 149 & 149 \\
\hline
\end{tabular}

nagative hookworm species, on the other hand, was significant $(p=-0022)$. The FECT technique detected 80 cases of infection, while FLOTAC detected 97 positives. Understanding these two detection methods has a high value $(\mathrm{p}=0.76)$.

The FLOTAC and FECT were calculated in this study under the assumption that positive results from both techniques (combination) were considered to be "true prevalence." However, with this approach, specificity and PPV cannot be obtained. Because the combination was considered the "gold standard," an analysis was performed using a soft CAT maker to determine the sensitivity and NPV of both techniques.

The FLOTAC technique showed significantly higher in sensitivity and NPV compared with the FECT. Moderate sensitivity in diagnosing T.trichiura $(78 \%)$ and hookworm $(18 \%)$ was found in the FECT technique. Moderate NPV values are found for diagnosing T.trichiura species $(75 \%)$ and any infection (75\%). The sensitivity of FECT for diagnosing hookworm species is very low $(18 \%)$.

According to the table above, the geometic mean of infection intensity among schoolchildren is $751 \mathrm{EPG}$ for A. lumbricoides, $596 \mathrm{EPG}$ for T.trichiura, and 3 EPG for hookworm, as determined by FECT techniques. However, using FLOTAC techniques, the species $A$. lumbricoides, T.trichiura, and hookworm have 11452EPG, $1038 \mathrm{EPG}$, and $19 \mathrm{EPG}$, respectively.

In table 5, almost all infected children were classified as having a mild infection. There are some cases where FECT does not detect light infections. The FLOTAC technique can detect a few specific infections caused by $A$. lumbricoides and T.trichiura that are classified as moderate. All these techniques could only identify hookworm light infection in children.

FLOTAC had significantly higher sensitivity 
Table 6 Variation of Infection Intensity by Species (A.lumbricoides, T.trichiura, hookworm) between FECT and FLOTAC Technique

\begin{tabular}{llcc}
\hline \multirow{2}{*}{ Species } & & \multicolumn{2}{c}{ Technique } \\
\cline { 3 - 4 } A. lumbricoides & Sensitivity & FECT & FLOTAC \\
\cline { 2 - 3 } & Specitivity & $82 \%(71-92 \%)$ & $100 \%(100-100 \%)$ \\
& NPV & $100 \%(100-100 \%)$ & $100 \%(100-100 \%)$ \\
T.Trichiura & PPV & $92 \%(86-97 \%)$ & $100 \%(100-100 \%)$ \\
& Sensitivity & $100 \%(100-100 \%)$ & $100 \%(100-100 \%)$ \\
& Specitivity & $78 \%(76-86 \%)$ & $99 \%(97-100 \%)$ \\
Hookworm & NPV & $100 \%(100-100 \%)$ & $100 \%(100-100 \%)$ \\
& PPV & $75 \%(65-84 \%)$ & $98 \%(95-100 \%)$ \\
& Sensitivity & $100 \%(100-100 \%)$ & $100 \%(100-100 \%)$ \\
& Specitivity & $18 \%(5-41 \%)$ & $82 \%(75-90 \%)$ \\
Any infection* & NPV & $100 \%(100-100 \%)$ & $100 \%(100-100 \%)$ \\
& PPV & $94 \%(90-98 \%)$ & $99 \%(97-100 \%)$ \\
& Sensitivity & $100 \%(100-100 \%)$ & $100 \%(100-100 \%)$ \\
& Specitivity & $82 \%(75-90 \%)$ & $99 \%(97-100 \%)$ \\
& NPV & $100 \%(100-100 \%)$ & $100 \%(100-100 \%)$ \\
& PPV & $76 \%(66-86 \%)$ & $98 \%(94-100 \%)$ \\
& & $100 \%(100-100 \%)$ & $100 \%(100-100 \%)$ \\
\hline
\end{tabular}

* Individuals infected with at least one of the species

and NPV than FECT. The FECT technique had a moderate sensitivity throughout, it was able to identify T. trichiura (78\%) and hookworm (78\%). (78 percent) (18\%). The NPV for diagnose T. trichiura species was $75 \%$ and any infection was moderate $(76.5 \%)$. FECT has a very low sensitivity for identifying hookworm species.

\section{Discussion}

The current era's "preventive chemoterapy," particularly for STH human infections, has a tendency to ignore diagnostic aspects. Furthermore, STH infection has the potential to cause significant the public health burden. In terms of elimination in various epidemiological settings, an accurate diagnosis is required. It is also an essential component of proper patient management, as well as the design, implementation, and monitoring of community-based control programs. Our research findings support and validate the use of existing techniques for the in vivo diagnosis of A.lumbricoides, T.trichiura, and hookworm. The benefits and drawbacks of the comparing technique are also discussed.
The results of both formalin ethyl acetate concentration (FECT) and FLOTAC techniques show that the morbidity of STH infection among children in Nangapanda village is still high, with (FECT) at 53\% (79/149) and FLOTAC at $64.4 \%$ $(96 / 149)$. However, there is no difference in risk for infection between boys and girls. Incidence of STH case infection by age was divided by grade class (I-VI), with results ranging from $50 \%$ to $76.92 \%$. In almost every class, the infection rate was greater than $50 \%$. The highest infection rate was found in the third class of children aged 8 years, with a prevalence of $76.92 \%$.

The FECT technique is not more sensitive for detecting hookworms than A. lumbricoides and T. trichiura based on research and the literature Furthermore, as per studies by Steffanie et al., FECT uses ether, which can impact intestinal worm eggs. The low sensitivity of FLOTAC in detecting hookworms may be due to the fact that the sample feces are stored in $5 \%$ formalin, which can affect the condition of hookworm eggs. The decreased sensitivity of FLOTAC in samples stored for more than 6 months in sodium acetate acetic acid-formalin (SAF). In his study, samples stored for less than 6 months using different flotation solutions (FS) and ether in the 
washing phase had a positive effect on detecting worm. What is suitable for one parasite may not be suitable for another. The results obtained at this time cannot be generalized, but there is a need for optimization of the FLOTAC technique, particularly for samples stored for a long time, so that the reliability and validity are required to identify hookworms in particular. The use of formalin for preservation for more than 6 months can affect or damage hookworm eggs. ${ }^{14}$

Observations in the field revealed that schools are located in areas far from health care (PHC), and students still do not wear footwear (bare foot), and students must remove footwear during learning activities in the class, which is mandatory for all school tenants.

The majority of Nangapanda's population is low-income. T. trichiura infection appears to be the most common among school-aged children (70), followed by A.lumbricoides infection (41) and hookworm infection (2). These findings indicate that helmintiasis is still a public health concern in the Ende District, and that it requires significant attention both diagnostically and controllably. As a result, using the current WHO-recommended strategy, intestinal worm infection, also known as Neglected Topical Disease (NTD), can be effectively eliminated and prevented.

FLOTAC had a sensitivity of $100 \%, 98 \%$, and $82 \%$ for diagnosing T. Trichiura, A. lumbricoides, and hookworm infections, respectively, whereas FECT had a sensitivity of $82 \%, 75 \%$, and $18 \%$. Within those three scenarios, the NPV of FLOTAC is extremely high. Throughout terms of diagnosing hookworm, FECT has a very low sensitivity. FLOTAC had significantly higher mean faecal egg counts $(11452,1038,19$ eggs per gram stool (EPG) for A. lumbricoides, T. Trichiura, and hookworm). When it came to diagnosing soiltransmitted helminth infections, the FLOTAC technique was far more sensitive than FECT. Finally, FLOTAC has the potential to be used as a diagnostic tool in future helminth control programs. We use the "CATmaker" analytics to predict the sensitivity and specificity of the FLOTAC and FECT) techniques. This software can be used to create Critically Approved Topics, therapies, diagnosis, prognosis, aetiology/harm, and a systematic review of therapy. Positive results from both techniques are regarded the "gold standard" and the true prevalence. Specificity and positive predictive value (PPV) may be impossible to achieve with this. ${ }^{12}$

These findings were analyzed using CATmaker software, specifically the diagnosis of STH infection with the FLOTAC technique on all positive and negative samples, regardless of species, with a sensitivity of $100 \%(100-100,95$ $\% \mathrm{CI})$ and an NPV of $100 \%$ (100-100, CI95 \% ). All species of STH worms were examined. While the FECT technique has an $82 \%$ sensitivity and a 75\% NPV in diagnosing any infection. This is consistent with the findings of Kassahun Habtamu et al. in Ethiopia, who discovered that FLOTC has a sensitivity of 100\% (97.5-100, 95\% CI) and an NPV of FLOTAC techniques were found to be more sensitive than multiple Kato-Katz thick smears for the diagnosis of hookworms, A. lumbricoides, and T. trichiura infections. one hundred \% (94.1-100, $95 \% \mathrm{CI}) .{ }^{10}$ When compared to multiple Kato-Katz thick smears for the diagnosis of hookworms, A. lumbricoides, and T. trichiura infections, Ngwese et al reported that FLOTAC techniques were more sensitive. ${ }^{9}$

Nikolay et.al found that the FLOTAC method had the higher specificity at low intensity, at 81.8 \% (95\% BCI (Bayesian Credible Intervals): $65.5-90.3 \%$ ), compared to $97.1 \%$ (95\% BCI: $93.1-99.7 \%$ ) at high intensity. ${ }^{7}$

Based on WHO criteria, almost all of the children were classified as having mild infections. According to the FLOTAC technique, three (5.8 $\%$ ) of people had moderate infections (500049999) of $A$. lumbricoides, while 47 (94\%) had mild infections (1-4999 EPG). FLOTAC classified one T. trichiura infection as moderate (10009999 EPG) and 90 (98.8\%) as mild (1-999 EPG). FLOTAC identified 9 cases (5.96\%) of mild infections (1-1999 EPG). The FECT technique detects only $41(36.52 \%$ ) of people with a mild infection (1-4999) for the species A. lumbricoides and T.trichiura $71(61.73 \%)$ of people with a mild infection (1-999 EPG), and 2 (1.73\% ) of people with a severe infection (1-4999).

The sensitivity and specificity of the FLOTAC examination technique for worm infections, particularly A. lumbricoides and T. trichiura species, to the formalin ether or formalin ethyl acetate (FEC) examination technique is quite high, with $>90 \%$ for any infection. In contrast, sensitivity was rated low for hookworm species due to the short duration of the study. FLOTAC rates EPG as very sensitive in terms of sensitivity. Furthermore, the FLOTAC technique has a high NPV, which is useful for assessing therapeutic effectiveness and patient management.

Given the high cost of collecting stool samples in the field and then analyzing them in the laboratory, WHO recommends mass treatment as a preventive measure for high-risk groups in endemic areas. In endemic areas, where 
morbidity control has been shifting to infection and transmission control, an assessment of the epidemiological situation is required, and diagnosis is critical. Given the high operational costs of the helminthiasis prevalence survey, the elimination of intestinal worms through mass treatment is the most likely option for Indonesia. However, this option necessitates the use of a sensitive diagnostic technique. Currently, the molecular biology examination technique, PCR, has proven to be very sensitive, but it is not applicable on a large scale and is prohibitively expensive. ${ }^{9}$

Concentration and Kato Katz techniques have been proposed for detecting STH infection. Fresh faecal samples, on the other hand, must be examined immediately using the Kato Katz method because they can affect egg condition and examination results, particularly for hookworm species. The FLOTAC technique does not necessitate immediate examination because the samples are preserved with SAF or formalin, The FLOTAC technique is ideal for large sample sizes and difficult survey areas. Furthermore, stool samples preserved for up to 83 days can be used. ${ }^{9}$

In terms of cost, Kato-Katz method is less expensive than the Mini-FLOTAC (US\$10.14 vs. US $\$ 13.11$ for school-based sampling and US $\$ 11.99$ vs. US $\$ 14.96$ for community sampling) which is similar with Zanzibar study the unit cost for a single Kato Katz technique was $\$ 1.73$, the dual Kato Katz technique was $\$ 2.05$, and the FLOTAC technique was $\$ 2.35 .{ }^{15}$

The FLOTAC method is more expensive than Kato Katz because the preparation and reading stages are longer, but FLOTAC has a higher sensitivity. As a result, the cost is higher, but the results are more promising.

In conclusion, FLOTAC technique has high negative predictive value (NPV) and accuracy in diagnosing STH infection (A.lumbricoides, T.trichiura and hookworm). This FLOTAC technique could be used to investigate STH infection and assess the effectiveness of deworming programs.

Finally, the FLOTAC technique has a high negative predictive value (NPV) and accuracy when it comes to diagnosing STH infection (A.lumbricoides, T.trichiura and hookworm). This FLOTAC technique could be used to diagnose STH infection and evaluate deworming program effectiveness.

\section{Acknowledgements}

We would like to everyone at Public Primary School Pau Pau in Nangapanda, Ende District, East Nusa Tenggara Province for their participation in this research.

\section{References}

1. Jourdan PM, Lamberton PHL, Fenwick A, Addiss DG. Soil-transmitted helminth infections. Lancet. 2018;391(10117):25265.

2. Montresor A, Trouleau W, Mupfasoni D, Bangert M, Joseph SA, Mikhailov A, et al. Preventive chemotherapy to control soiltransmitted helminthiasis averted more than 500000 DALYs in 2015. Trans R Soc Trop Med Hyg. 2017;111(10):457-63.

3. Kurscheid J, Laksono B, Park MJ, Clements ACA, Sadler R, McCarthy JS, etal. Epidemiology of soil-transmitted helminth infections in semarang, central java, indonesia. PLoS Negl Trop Dis. 2020;14(12):1-17.

4. Moser W, Schindler C, Keiser J. Efficacy of recommended drugs against soil transmitted helminths: Systematic review and network meta-analysis. BMJ. 2017;358:1-10.

5. WHO.AssessingTheEfficacyOfAnthelminthic Drugs Against Schistosomiasis And SoilTransmitted Helminthiases. Vol. 148. 2013. 1-38 p.

6. Solomon AW, Engels D, Bailey RL, Blake IM, Brooker S, Chen JX, et al. A diagnostics platform for the integrated mapping, monitoring, and surveillance of neglected tropical diseases: Rationale and target product profiles. PLoS Negl Trop Dis. 2012;6(7):1-5.

7. Nikolay B, Brooker SJ, Pullan RL. Sensitivity of diagnostic tests for human soil-transmitted helminth infections: A meta-analysis in the absence of a true gold standard. Int J Parasitol. 2014;44(11):765-74.

8. Brummaier $\mathrm{T}$, Archasuksan L, Watthanakulpanich D, Paris DH, Utzinger J, McGready R, et al. Improved detection of intestinal helminth infections with a formalin ethyl-acetate-based concentration technique compared to a crude formalin concentration technique. Trop Med Infect Dis. 2021;6(2).

9. Ngwese MM, Manouana GP, Moure PAN, Ramharter $M$, Esen $M$, Adégnika AA. Diagnostic techniques of soil-transmitted 
helminths: Impact on control measures. Trop Med Infect Dis. 2020;5(2):1-8.

10. Habtamu K, Degarege A, Ye-Ebiyo Y, Erko B. Comparison of the Kato-Katz and FLOTAC techniques for the diagnosis of soiltransmitted helminth infections. Parasitol Int. 2011;60(4):398-402.

11. Bujang MA, Adnan TH. Requirements for minimum sample size for sensitivity and specificity analysis. J Clin Diagnostic Res. 2016;10(10):YE01-6.

12. Moralejo D, Ogunremi T, Dunn K. Critical Appraisal Toolkit ( CAT ) for assessing multiple types of evidence. Can Commun Dis Rep. 2017;43:176-81.
13. Cringoli G. FLOTAC, a novel apparatus for a multivalent faecal egg count technique. Parassitologia. 2006;48(3):381-4.

14. Knopp S. Diagnosis, epidemiology and control of soil-transmitted helminth infections in Zanzibar , Tanzania. In University of Basel; 2011. p. 1-45. Available from: http://edoc. unibas.ch/diss/DissB_9646

15. Assefa LM, Crellen T, Kepha S, Kihara JH, Njenga SM, Pullan RL, et al. Diagnostic accuracy and cost-effectiveness of alternative methods for detection of soiltransmitted helminths in a post-treatment setting in Western Kenya. PLoS Negl Trop Dis. 2014;8(5):e2843. 